\title{
Hydroxyapatite/Carboxymethyl Cellulose Composite: Synthesis, Characterization, Kinetic, Thermodynamic Study for Removal of Cr (III)
}

\author{
Zahra Abbasi ${ }^{1 *}$, Elham Ramezani ${ }^{1}$, Abdolhadi Farrokhnia ${ }^{1}$, Atefeh Sayadi Shahraki², Abd Ali Naseri ${ }^{2}$
}

${ }^{1}$ Chemistry Department, College of Science, Shahid Chamran University of Ahvaz, Ahvaz, Iran.

${ }^{2}$ Water Science Engineering

Department, Shahid Chamran

University of Ahvaz, Ahvaz, Iran.

\section{*Corresponding Author: \\ $\rightarrow$ email}

Received: 20 November, 2020

Accepted: 10 January, 2021

Published: 15 January, 2021

\begin{abstract}
In the present work nano-hydroxyapatite (n-HAp)/Carboxymethyl Cellulose (CMC) composite was synthesized. The n-HApCMC composite was tested for the adsorption of Chromium from aqueous solution and compared its removal capacity with nano-hydroxyapatite (n-HAp). Equilibrium data were fitted well in the Langmuir and Freundlich isotherm models. The thermodynamic analysis also established that the adsorption process was endothermic and spontaneous.
\end{abstract}

Keywords: Adsorption, Heavy metals, Isotherm, Nano-hydroxyapatite/Cellulose

\section{Introduction}

Heavy metal pollution has become an environmental problem throughout the world because heavy metals can be accumulated into the food chain and cause serious problems, not only for ecosystems but also for human health [1-5]. Hydroxyapatite $\mathrm{Ca}_{10}\left(\mathrm{PO}_{4}\right)_{6}(\mathrm{OH})_{2}$ (HAp) is a main mineral constituent of teeth, bones and phosphate mineral rocks. It belongs to apatite mineral family [6] However, characteristic of HAp existing in the form of white powder therefore isolating the suspended fine solids from aqueous solutions after adsorption of metal ions is not easy [7]. The annual net yield of photosynthesis is 1.8 trillion tonnes of biodegradable substances, about $40 \%$ of which is estimated to be cellulose [8]. Hence the general aim of the study is to investigate adsorption capability of cellulose composites made with nano-hydroxyapatite which, biocompatibility, biodegradability, etc than the individual components and hence be utilized at field conditions. Hybrid polymeric composites namely nanohydroxyapatite (n-HAp)/Carboxymethyl Cellulose (CMC) were prepared and used for the removal of
Cr(III) from drinking water which has not been reported so far. Various parameters namely contact time, $\mathrm{pH}$, coions and temperature were optimized for maximum sorption. The best fit isotherm was identified for the sorption. Suitable mechanism of $\mathrm{Cr}(\mathrm{III})$ removal was proposed.

\section{Methods}

Synthesis of Nano-Hydroxyapatite (n-HAp)/ Carboxymethyl Cellulose (CMC) Composite

The corresponding n-HApCMC composites were prepared by the precipitation method. The aqueous solution of ammoniumdihydrogen phosphate was added to the mixture of aqueous solution of $\mathrm{Ca}\left(\mathrm{NO}_{3}\right)_{2}$ with $\mathrm{CMC}$ in the ratio 3:2. The precipitate formed was rinsed with water to reach $\mathrm{pH}$ 7. The precipitate obtained was dried at $80{ }^{\circ} \mathrm{C}$ to get n-HApCMC composites [9]. 


\section{Results and discussion}

\section{Characterization of materials}

The FT-IR spectra of n-HApCMC (A), CMC (B) and $\mathrm{n}-\mathrm{HAp}(\mathrm{C})$ were recorded in the region of 500-4000 $\mathrm{cm}^{-1}$ and are shown in Fig. 1. The spectra of $\mathrm{n}-\mathrm{HAp}$ showed a broad band at $1203 \mathrm{~cm}^{-1}$ due to asymmetric stretching of $\mathrm{PO}_{4}{ }^{3-}$ and corresponding symmetric stretching was observed at $875 \mathrm{~cm}^{-1}$. The absorption band at $1487 \mathrm{~cm}^{-1}$ suggested the presence of $\mathrm{CO}_{3}{ }^{2-}$ [9], which was supposed to have come from atmosphere during the precipitation process. The broad band at
3500 to $3200 \mathrm{~cm}^{-1}$ and $1766 \mathrm{~cm}^{-1}$ was due to stretching and bending of $\mathrm{O}-\mathrm{H}$ groups, respectively, present in nHAp [10]. The FT-IR spectra of n-HApCMC showed a band at $1032 \mathrm{~cm}^{-1}$ which was due to stretching vibration of $\mathrm{C}-\mathrm{O}-\mathrm{C}$ group of $\mathrm{CMC}$ confirms formation of composite. The peak of $\mathrm{PO}_{4}{ }^{3-}$ group shifted from 1203 to $1132 \mathrm{~cm}^{-1}$ due to interaction with CMC. The stretching and bending vibration mode of $\mathrm{OH}$ group of CMC occurred at 3452 and $1627 \mathrm{~cm}^{-1}$, respectively which was overlapped with the bands of $\mathrm{O}-\mathrm{H}$ groups in $\mathrm{n}-\mathrm{HApCMC}$ composite.

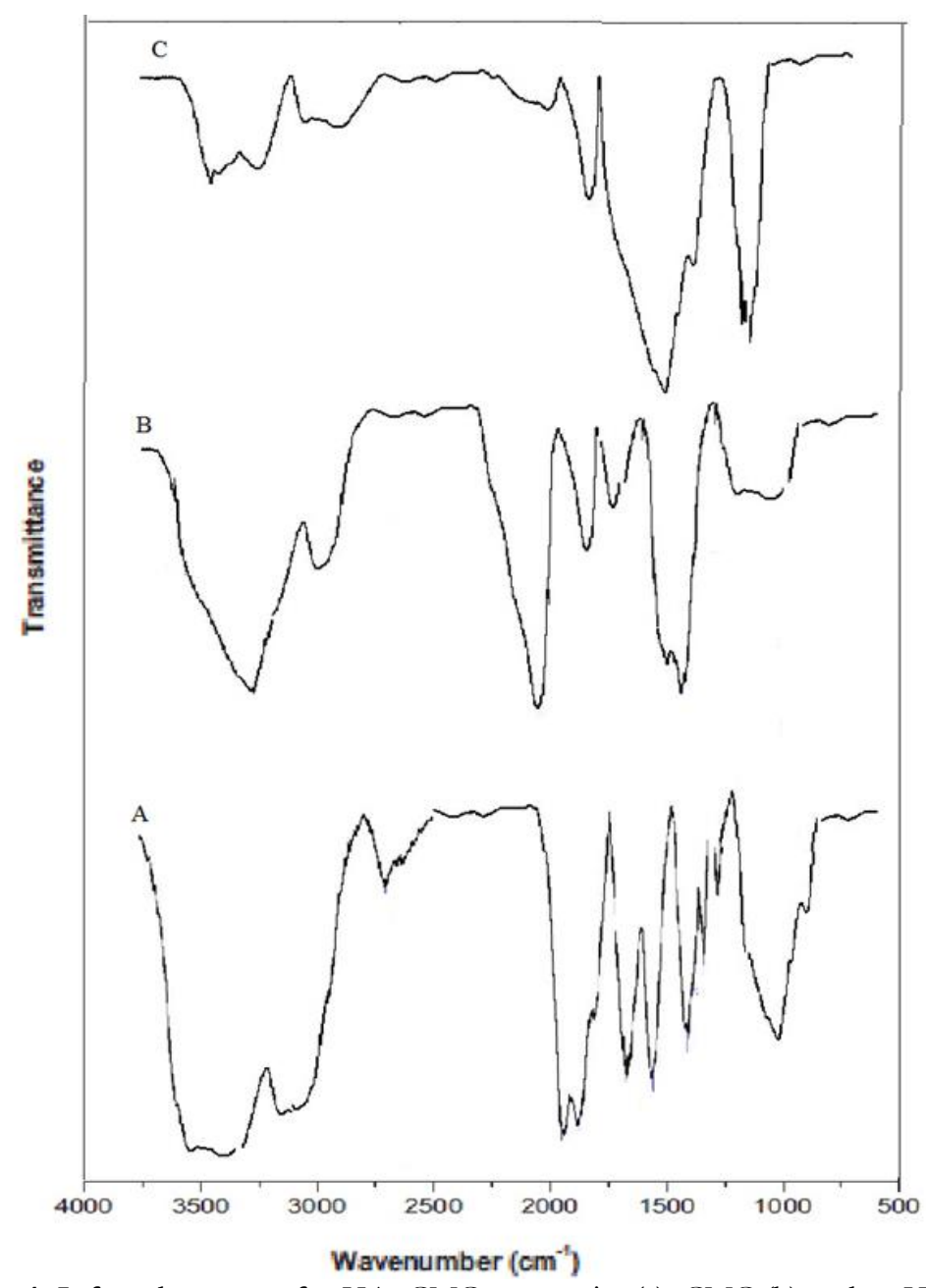

Figure 1. Infrared spectra of n-HApCMC composite (a), CMC (b) and n- HAp (c).

The XRD spectra of CMC, n-HAP and n-HApCMC are shown in Fig. 2. In the XRD pattern of n-HAp, the crystalline peaks at $2 \theta=25.9^{\circ}, 31.9^{\circ}, 32^{\circ}, 34.5^{\circ}$ and $40^{\circ}$ confirm the formation of hydroxyapatite. Crystalline peaks of In Fig. 2B, two main diffraction peaks of $\mathrm{CMC}$ at $2 \theta=32^{\circ}$ and $46^{\circ}$ can be found.n-HAp at $2 \theta=$ $26^{\circ}, 32^{\circ}, 33.1^{\circ}, 34.2^{\circ}, 39.9^{\circ}$ and $46^{\circ}$ were found in $n-$ HApCMC. This indicated that there was no marked change in the peak structure after the composite formation and confirms that the crystal structure of $n$ HAp is retained in $\mathrm{n}-\mathrm{HApCMC}$ composites. 


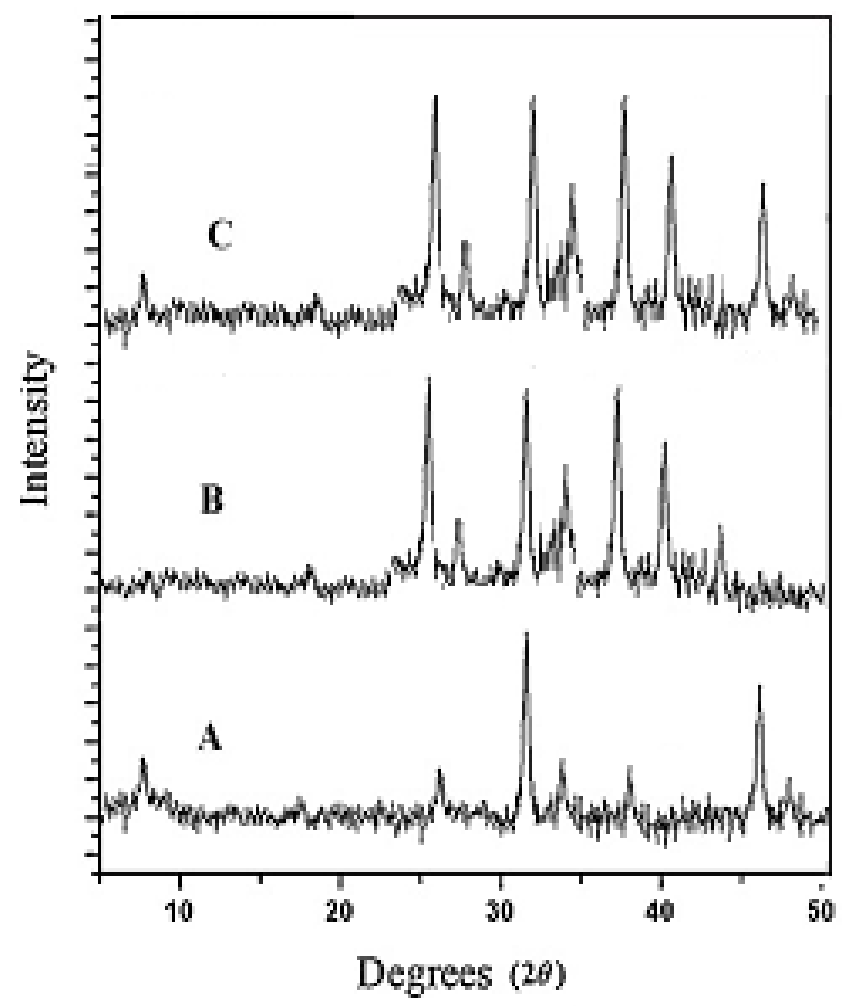

Figure 2. XRD spectra of CMC (a), HAp (b) and n-HApCMC (c).

Fig. 3 shows the morphology of n-HAp (a) and nHApCMC composite (b). The n-HAp powder exhibited as particles but in case of $\mathrm{n}$-HapCMC composite aggregates appeared and film of CMC over $\mathrm{n}-\mathrm{HAp}$, confirmed the formation of $\mathrm{n}-\mathrm{HApCMC}$ composite.

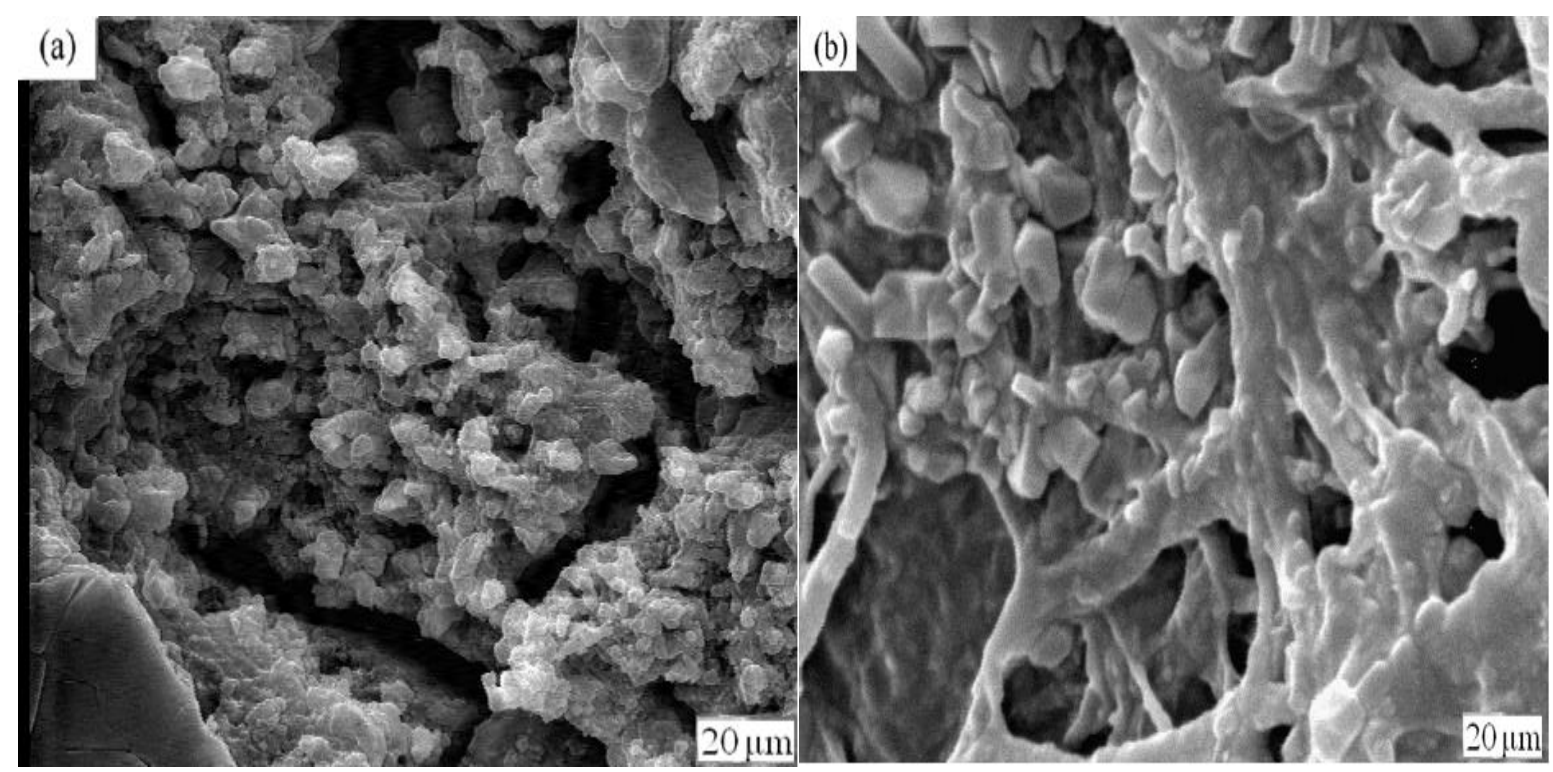

Figure 3. SEM micrograph of n-HAp (a) and n-HApCMC composite (b).

\section{Equilibrium modeling in a batch system}

Analysis of equilibrium data is important for developing an equation that can be used to compare different biomaterials under different operational conditions and to design and optimize an operating procedure. The Langmuir and Freundlich equations are 
commonly used for describing adsorption equilibrium for water and wastewater treatment applications. Two important physicochemical aspects for the evaluation of the adsorption process as a unit operation are the equilibrium of the adsorption and the kinetics. Equilibrium studies give the capacity of the adsorbent. The equilibrium relationships between the adsorbent and the adsorbate are described by the adsorption isotherms. The adsorption curves were applied to both the Langmuir and Freundlich equations. The Freundlich isotherm model, which assumes that the adsorption occurs on heterogeneous surfaces, is often expressed as;

$$
q_{e}=K_{f}\left(C_{e}\right)^{1 / n}
$$

This equation is conveniently used in the following linear form:

$\ln q_{e}=\ln K_{f}+\frac{1}{n} \ln C_{e}$

Where $K_{\mathrm{f}}$ is Freundlich isotherm constant $\left(\mathrm{L} \mathrm{g}^{-1}\right)$ and $\mathrm{n}_{\mathrm{F}}$ is Freundlich isotherm exponent. Values of $\mathrm{K}_{\mathrm{F}}$ and $\mathrm{n}_{\mathrm{F}}$ were calculated from the intercept and slope of plots $\ln \mathrm{q}_{\mathrm{e}}$ vs $\ln \mathrm{C}_{\mathrm{e}}$ and a straight line indicates the confirmation of the Freundlich isotherm for adsorption. The value of $n_{F}$ should be greater than one confirming good adsorption of heavy metals onto nHapCMC composite. Langmuir isotherm, which assume that a monolayer of heavy metals is formed on a relatively regular adsorbent surface, using the partially protonated groups of the adsorbent. The Langmuir isotherm has been successfully applied to many real sorption processes and is expressed as follows:

$q_{e}=\frac{Q^{0} b C_{e}}{1+b C_{e}}$

Where $\mathrm{q}_{\mathrm{e}}$ is the amount adsorbed at equilibrium (mg g$\left.{ }^{1}\right), C_{e}$ the equilibrium concentration $\left(\mathrm{mg} \mathrm{L}^{-1}\right), \mathrm{b}$ a constant related to the energy or net enthalpy of adsorption $\left(\mathrm{L} \mathrm{mg}^{-1}\right)$, and $\mathrm{Q}_{0}$ the mass of adsorbed solute required to saturate a unit mass of adsorbent $(\mathrm{mg}$ $\left.\mathrm{g}^{-1}\right)$. $\mathrm{Q}_{0}$ represents a practical limiting adsorption capacity when the surface is fully covered with heavy metals and allows the comparison of adsorption performance, particularly in the cases where the adsorbent did not reach its full saturation in experiments. The Langmuir equation can be described by the linearized form as follows:

$\frac{C_{e}}{q_{e}}=\frac{1}{Q^{0} b}+\frac{C_{e}}{Q^{0}}$

By plotting $\left(\mathrm{C}_{\mathrm{e}} / \mathrm{q}_{\mathrm{e}}\right)$ versus $\mathrm{C}_{\mathrm{e}}, \mathrm{Q}^{0}$ and $\mathrm{b}$ can be determined if a straight line is obtained. The essential characteristics of Langmuir isotherm can be expressed in terms of a dimensionless constant, separation factor or equilibrium parameter, $\mathrm{R}_{\mathrm{L}}$, which is defined by:

$R_{L}=\frac{1}{1+b C_{0}}$

Where $\mathrm{b}$ is the Langmuir constant and $\mathrm{C}_{0}$ the initial heavy metals concentration $\left(\mathrm{mg} \mathrm{L}^{-1}\right)$. $\mathrm{R}_{\mathrm{L}}$ value indicates the type of isotherm. According to [12], $\mathrm{R}_{\mathrm{L}}$ values between 0 and 1 indicate favorable adsorption. For evaluating the adsorption kinetics the pseudo-firstorder and pseudo-second-order kinetic models were used to fit the experimental data. It was observed that the $\mathrm{q}_{\mathrm{e}}$ values estimated by first-order kinetic model differ substantially from those measured experimentally, suggesting that the adsorption is not a first-order reaction. The correlation coefficients for the second-order kinetic model are nearly equal to 1 and the theoretical values of $\mathrm{q}_{\mathrm{e}}$ also agree very well with the experimental values. This suggests that the adsorption of heavy metals on n-HapCMC follows the secondorder kinetic model. Tab. 4 and Fig. 6 and 7.

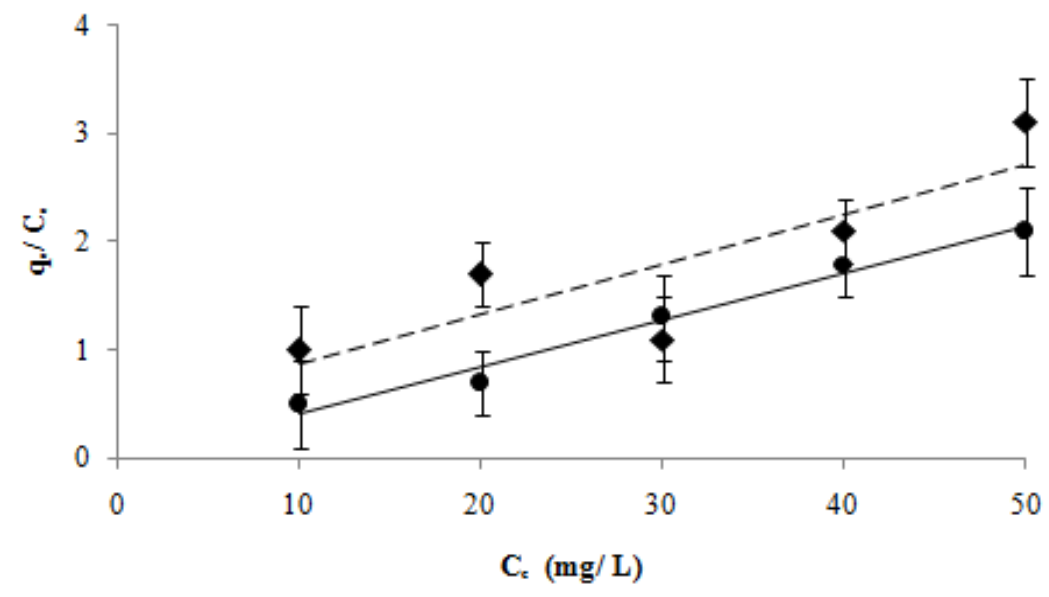

Figure 6. Langmuir adsorption isotherm at $293^{\circ} \mathrm{K}$. 
Table 4

Freundlich and Langmuir adsorption isotherm constants.

\begin{tabular}{lcccccc}
\hline & \multicolumn{3}{c}{ Langmuir constants } & \multicolumn{3}{c}{ Freundlich constants } \\
\cline { 2 - 7 } & $\left.\mathbf{Q}^{\circ} \mathbf{( m g} / \mathbf{g}\right)$ & $\mathbf{b}(\mathbf{L} / \mathbf{m g})$ & $\mathbf{R}^{\mathbf{2}}$ & $\mathbf{K}_{\mathbf{F}}(\mathbf{L} / \mathbf{m g})$ & $\mathbf{n}$ & $\mathbf{R}^{\mathbf{2}}$ \\
\hline n-HAp & 9.03 & 0.276 & 0.998 & 2.13 & 1.82 & 0.997 \\
n-HApCMC & 12.89 & 0.612 & 0.997 & 4.09 & 1.58 & 0.994 \\
\hline
\end{tabular}

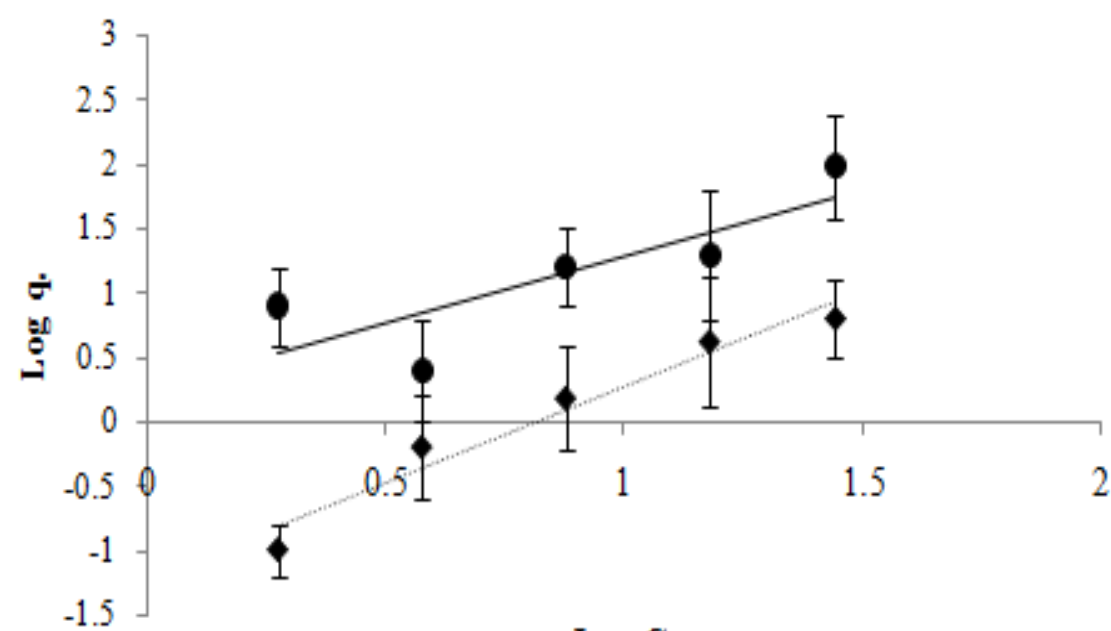

$\log C_{c}$

Figure 7. Freundlich adsorption isotherm at $293^{\circ} \mathrm{K}$.

The effect of temperature on the adsorption of heavy metals on $\mathrm{n}$-HapCMC was investigated by conducting experiments for $100 \mathrm{mg} / \mathrm{L}$ of initial metals ion concentrations at $293,303,308,313$, and $318^{\circ} \mathrm{K}$. It was observed that on increasing the temperature percentage removal of heavy metals increased. This showed that the adsorption process was endothermic in nature.

The thermodynamic parameters Gibb's free energy $\left(\Delta G^{\circ}\right)$, enthalpy $(\Delta H)$ and entropy $\left(\Delta S^{\circ}\right)$ were calculated using the following equations:

$\ln \left(\frac{q_{e} m}{C_{e}}\right)=\frac{\Delta s^{0}}{R}+\frac{-\Delta H^{0}}{R T}$

$\Delta G^{0}=\Delta H-T \Delta S^{0}$
Where $\mathrm{m}$ is the adsorbent dose $\left(\mathrm{g} \mathrm{L}^{-1}\right), \mathrm{C}_{\mathrm{e}}$ is concentration of metals ion $\left(\mathrm{mg} \mathrm{L}^{-1}\right), \mathrm{q}_{\mathrm{e}}$ is the amount of metals ion at equilibrium in unit mass of adsorbent $\left(\mathrm{mg} \mathrm{g}^{-1}\right), \mathrm{q}_{\mathrm{e}} / \mathrm{C}_{\mathrm{e}}$ is called the adsorption affinity. $\Delta \mathrm{H}$, $\Delta S^{\circ}$ and $\Delta G^{\circ}$ are change in enthalpy $\left(\mathrm{kJ} \mathrm{mol}^{-1}\right)$, entropy $\left(\mathrm{J}(\mathrm{mol} \mathrm{K})^{-1}\right)$ and free energy $\left(\mathrm{kJ} \mathrm{mol}^{-1}\right)$, respectively. $\mathrm{R}$ is the gas constant $\left(8.314 \mathrm{~J} \mathrm{~mol}^{-1} \mathrm{~K}^{-1}\right.$ ) and $\mathrm{T}$ is the temperature $(\mathrm{K})$.

The values of $\Delta \mathrm{H}$ and $\Delta \mathrm{S}^{\circ}$ were obtained from the slopes and intercepts of the Van't Hoff plots of $\ln$ $\left(\mathrm{q}_{\mathrm{e}} \mathrm{m} / \mathrm{C}_{\mathrm{e}}\right.$ ) vs. $1 / \mathrm{T}$, respectively, thereafter $\Delta \mathrm{G}^{\circ}$ values were determined from Eq. (13). The values of thermodynamic parameters are presented in Table 5. The results showed that the $\Delta G^{\circ}$ values are negative and increased in their absolute values with temperature [13].

Table 5

Thermodynamic parameters for adsorption of Cr (III) on n-HApCMC and n-Hap.

\begin{tabular}{lccccccc}
\hline & $\begin{array}{c}\boldsymbol{\Delta} \mathbf{H}^{\circ} \\
(\mathbf{k J} / \mathbf{m o l})\end{array}$ & $\begin{array}{c}\boldsymbol{\Delta} \mathbf{S}^{\circ} \\
(\mathbf{J m o l} / \mathbf{K})\end{array}$ & & \multicolumn{5}{c}{$\begin{array}{c}\mathbf{\Delta} \mathbf{G}^{\circ} \\
\mathbf{( k J / m o l})\end{array}$} \\
\cline { 2 - 8 } & & & $\mathbf{2 9 3}^{\circ} \mathbf{K}$ & $\mathbf{3 0 3}^{\circ} \mathbf{K}$ & $\mathbf{3 0 8}^{\circ} \mathbf{K}$ & $\mathbf{3 1 3}^{\circ} \mathbf{K}$ & $\mathbf{3 1 8}^{\circ} \mathbf{K}$ \\
\hline n-HAp & 42.769 & 171.759 & 8.415 & 9.273 & 10.132 & 10.991 & 11.850 \\
n-HApCMC & 57.823 & 223.871 & 8.890 & 10.001 & 11.129 & 12.248 & 13.368 \\
\hline
\end{tabular}


This result suggested that a high temperature is favoured for the adsorption of heavy metals on $n$ HapCMC composite, indicated a spontaneous adsorption process. The values of heat of adsorption, $\Delta \mathrm{H}$ is positive for metals ion, indicated that the adsorption process of heavy metals on n-HapCMC composite was endothermic. A positive $\Delta S$ suggested that heavy metals were not stable on the adsorption sites of n-HapCMC composite probably due to the increase in translational energy of metals ion.

\section{Conclusion}

This study showed that the binding of nano-HAp powder with cellulose makes it convenient to use practically and its removal capability was also retained in $\mathrm{n}$-HApCMC which makes n- HApCMC composite as an effective adsorbent for the removal of $\mathrm{Cr}$ (III) from aqueous solution. Taguchi statistical method as an efficient, effective, and without the need for a large number of experiments indicated that the Hydroxyapatite/ Carboxymethyl Cellulose nanocomposite as a new adsorbent, no cost, and without secondary pollutant has a high efficiency for $\mathrm{Cr}$ (III) removal from aqueous solution. The adsorption process followed pseudo-second-order kinetics and obeyed Langmuir adsorption isotherm for metal ions studied. The negative values of $\Delta G^{\circ}$ suggested that the adsorption was spontaneous in nature. The positive value of $\Delta \mathrm{H}$ and $\Delta \mathrm{S}$ indicated endothermic adsorption process and increased randomness at surface-solution interface, respectively.

\section{References}

1. Ghanbari Pakdehi Sh, Alipour M. Adsorption of $\mathrm{Cr}(\mathrm{III})$ and $\mathrm{Mg}$ (II) from Hydrogen Peroxide Aqueous Solution by Amberlite IR-120 Synthetic Resin. Iran J Chem Chem Eng. 2013; 32(2): 49.

2. Nekoo SH, Fatemi Sh. Experimental study and adsorption modeling of COD reduction by activated carbon for wastewater treatment of oil refinery. Iran $J$ Chem Chim Eng. 2013; 32(3): 81-89.

3. Kumar Jha M, Van Nguyen N, Lee J, Jeong J, Yoo J. Adsorption of copper from sulphate solution of low copper contents using the cationic resin amberlite IR120. J Hazard Mater. 2009; 164: 948.

4. Shakeri A, Hazeri N, Valizadeh J, Hashemi E, Kakhky A. Removal of Lead (II) from aqueous solution using cocopeat: An investigation on the isotherm and kinetic. Iran J Chem Chem Eng. 2012; 31: 45-50.

5. Cavaco SA, Fernandes S, Augusto CM, Quina MJ, Gando-Ferreira LM. Evalution of chelating ionexchange resins for separating $\mathrm{Cr}(\mathrm{III})$ from industrial effluent. J Hazard Mater. 2009; 169: 516.

6. Bailliez S, Nzihou A, Beche E, Flamant G. Removal of Lead $(\mathrm{Pb})$ by hydroxyapatite sorbent. Process Saf Environ Protect. 2004; 82: 175-180.

7. Simon FG, Birmann V, Peplinski B. Uranium removal from groundwater using hydroxyapatite. Appl Geochem. 2008; 23: 2137-2145.

8. Choi S, Jeong Y. The removal of heavy metals in aqueous solution by hydroxyapatite/cellulose composite. Fiber Polym. 2008; 9: 267-270.

9. Mobasherpour I, Heshajin MS, Kazemzadeh A, Zakeri M. Synthesis of nanocrystalline hydroxyapatite by using precipitation method. J Alloy Compd. 2007; 430: 330-333.

10. Leyva AQG, Marrero J, Smichowski P, Cicerone D. Sorption of antimony onto hydroxyapatite. Environ Sci Technol. 2001; 35: 3669-3675.

11. Pacyna EG, Pacyna JM, Pirrone N. European emissions of atmospheric mercury from anthropogenic sources in 1995. Atmos Environ. 2001; 35: 2987-2996.

12. McKay G, Blair HS, Gardener JR. Adsorption of dyes on chitin. I. Equilibrium studies. I Appl Polym Sci. 1982; 27: 3043-3057.

13. Abbasi Z, Alikarami M. Kinetics and thermodynamics studies of acetic acid adsorption from aqueous solution by peels of banana. Biochem Bioinform. 2012; 1(1): 001-007.

14. Zolfagharia G, Esmaili-Sari A, Anbia M, Younesi H, Amirmahmoodi S, Ghafari Nazari MJ. Hazard. Mater. 2011; 192: 1055.

15. Sadeghi S, Moosavi H, Karami VA, Behnia J. Hydrol. 2012; 180: 448-449.

16. Taguchi G. Introduction to quality engineering. 1990; McGraw-Hill New York, USA.

\section{ALKHAS}

Copyright: (C) 2020 The Author(s); This is an open-access article distributed under the terms of the Creative Commons Attribution License (http://creativecommons.org/licenses/by/4.0), which permits unrestricted use, distribution, and reproduction in any medium, provided the original work is properly cited.

Citation: Abbasi Z, Ramezani E, Abdolhadi Farrokhnia, Sayadi Shahraki A, Naseri AA. Hydroxyapatite/Carboxymethyl Cellulose Composite: Synthesis, Characterization, Kinetic, Thermodynamic Study for Removal of Cr (III). ALKHAS. 2021; 3(1): 12-17.

https://doi.org/10.47176/alkhass.3.1.12 